\title{
Ley de Voluntad Anticipada en Uruguay: una intención loable con algunas inconsistencias
}

\author{
Advance Directive Act in Uruguay: commendable intention with a few inconsistencies \\ Lei de diretivas antecipadas de vontade no Uruguai: uma intenção louvável com \\ algumas inconsistências
}

\section{Frances Borches Duhalde ${ }^{1}$}

\section{Resumen}

La Ley № 18.473 y el Decreto que la reglamenta (385/013) fueron concebidos con la finalidad de dar un marco normativo a la posibilidad que tiene una persona de establecer sus preferencias sobre ciertos actos médicos cuando todavía es capaz de consentir, ejerciendo su autonomía de manera anticipada ante la eventual pérdida de capacidad de decisión. Por lo tanto, el hecho de llevar a cabo o no un procedimiento médico no dependerá de la capacidad de consentir de la persona en ese momento, esto es lo que la diferencia del consentimiento informado habitual.

Palabras clave: Ética

Directivas anticipadas

Voluntad en vida

Key words: $\quad$ Ethics

Advance directives

Living wills
Este artículo tiene como propósito analizar las posibles discrepancias que existen entre lo que se pretendió alcanzar al crear la ley y lo que realmente se puede realizar. Ciertos aspectos analizados podrían explicar, al menos en parte, por qué esta ley que ya cuenta con más de 12 años desde su promulgación sigue siendo de muy difícil implementación.

La palabra voluntad viene del latín voluntas, que según algunas definiciones del diccionario de la Real Academia Española hace referencia a: 1) la facultad de decidir y ordenar la propia conducta; 2 ) al acto con que la potencia volitiva admite o rehúye una cosa, queriéndola, o aborreciéndola y repugnándola; 3) Libre albedrío o libre determinación; 4) Elección de algo sin precepto o impulso externo que a ello obligue; 5) Consentimiento, asentimiento, aquiescencia. Por otro lado, algunos de los significados de la palabra anticipar son: hacer que algo tenga lugar antes del tiempo señalado o previsible, antes que otra cosa; anunciar algo antes de un momento dado, o antes del tiempo oportuno o esperable. En concreto, el concepto de voluntad anticipada hace referencia a la posibilidad que tiene una persona de ejercer su autonomía decidiendo sobre algo antes de que suceda; y puede ser considerada como una modalidad particular del consentimiento informado ${ }^{(1)}$.

A nivel mundial, específicamente en Estados Unidos, ya en la década de 1970 se empezaron a utilizar los testamentos vitales o poderes legales como instrumentos para establecer las preferencias o deseos de las personas de manera anticipada, en caso de encontrarse en una situación en la que no tenga capacidad de dar el consentimiento por sí misma ${ }^{(2)}$.

Como antecedente a la creación de la Ley de Voluntad Anticipada en 2009, en Uruguay ya existía la Ley $N^{\circ}$

\footnotetext{
1. Universidad de la República. Facultad de Medicina. Departamento de Medicina Legal y Ciencias Forenses.

La autora declara no tener conflicto de intereses.

Correspondencia: Frances Borches Duhalde. Correo electrónico: francesborches@fmed.edu.uy

Recibido: $15 / 4 / 2021$

Aprobado: 16/6/2021

Attribution-NonCommercial 4.0 International (CC BY-NC 4.0)
} 
14.005 de 1971 que creó el marco normativo para la donación y trasplante de órganos y tejidos: "se trata del primer antecedente legal nacional que establece y regula ciertas formas de directivas anticipadas",(3).

En 2009 se promulgó la Ley No 18.473 de Voluntad Anticipada y fue reglamentada por el Decreto 385/013. Esta norma establece la posibilidad de que cualquier persona "mayor de edad y psíquicamente apta, en forma voluntaria, consciente y libre” pueda ejercer su autonomía de manera anticipada para que se efectivice su elección en cuanto a su deseo o no de oponerse a ciertos tratamientos o procedimientos cuando se encuentre en un estado de incapacidad legal o natural. El decreto dispone que una persona es considerada mayor de edad cuando cumple los 18 años, y establece que no deberán probar su aptitud psíquica excepto que quien reciba esa expresión tenga dudas razonables al respecto, pudiendo "acreditarse aquella mediante la certificación médica correspondiente. En caso de que el receptor sea médico será él mismo quien evalúe la aptitud psíquica salvo que no se considere capacitado".

En el inciso segundo del artículo $1^{\circ}$ de la ley, dice que "tiene derecho de expresar anticipadamente su voluntad en el sentido de oponerse a la futura aplicación de tratamientos y procedimientos médicos que prolonguen su vida en detrimento de la calidad de la misma, si se encontrare enferma de una patología terminal, incurable e irreversible".

$\mathrm{Si}$ bien la finalidad de la ley parecería ser loable al darnos la potestad a las personas de anticiparnos a cualquier situación de salud y decidir de manera precoz cuál es nuestra preferencia, en el inciso citado anteriormente ya nos encontramos una redacción un tanto confusa; específicamente se está estableciendo la posibilidad de que el paciente nos permita hacer lo que estamos obligados a hacer. El Código de Ética Médica (Ley No 19.286) y la ley de Derechos y Obligaciones de Pacientes y Usuarios de los Servicios de Salud (Ley No 18.335 y su decreto reglamentario 274/010) establecen que los médicos tenemos la prohibición legal y ética de efectuar tratamientos o procedimientos que puedan ser considerados como fútiles, es decir, realizar conductas aún sabiendo que no existen "razonables expectativas de mejoría”. El Código de Ética es aún más preciso, ya que esgrime que no es éticamente admisible indicar "procedimientos diagnósticos o terapéuticos que sean innecesarios y eventualmente perjudiciales para su calidad de vida". En definitiva, nosotros como médicos no podemos llevar a cabo ninguna maniobra que empeore la calidad de vida del paciente en cuestión.

Pero lo más llamativo de este primer artículo es el inciso quinto; que choca de bruces con las leyes nombradas anteriormente al establecer que cualquier persona "podrá manifestar su voluntad anticipada en contrario a lo establecido en el inciso segundo de este artículo". Esto va totalmente a contrapelo al desarrollo de nuestra tarea como médicos de acuerdo a la lex artis. El oponerse al inciso segundo implicaría que el paciente puede solicitar que nuestra conducta sea fútil, es decir, innecesaria, y lo que es peor aún, es que incluso nos habilitaría a llevar a cabo ciertas conductas con las que no pretendemos mejorar al paciente aún sabiendo de la posibilidad de dañarlo. Cualquier conducta ajustada al inciso quinto iría en contraposición con los principios éticos de no maleficencia, beneficencia y justicia.

El cuarto artículo del decreto intenta matizar esta situación al hacer referencia a que en caso que la persona requiera que se le realicen tratamientos que puedan ser considerados fútiles: "el médico tratante ajustará su accionar terapéutico al estado de los conocimientos de las ciencias médicas referentes a la enfermedad del paciente y en caso de existir discordancia entre la voluntad en contrario expresada por aquél y la opinión del médico tratante, la situación será sometida a la mayor brevedad posible a la decisión de un ateneo". Si bien parecería parchear lo anterior, genera una falsa sensación de libertad a quien lo solicita y termina confundiendo el consentimiento -decisión informada del paciente- con la posibilidad de que el paciente le indique al médico el tratamiento que le debe proporcionar.

En los siguientes artículos tanto la ley como el decreto establecen que la persona debe elegir un representante para que sea el responsable de dar cumplimiento a sus solicitudes. Esto se debe realizar de manera escrita y con la firma de dos testigos ante un médico o escribano público. Una vez completado el formulario de voluntad anticipada, debe inmediatamente quedar agregado en la historia, en un lugar fácilmente ubicable y visible para que el médico pueda tener conocimiento de ese deseo para poder cumplirlo. Las instituciones prestadoras de salud son las responsables de la custodia y de la efectiva incorporación de estas voluntades a la historia clínica de cada paciente. Respecto a este formulario, dos apreciaciones: es genérico y simplemente se debe indicar si lo que estoy solicitando es que no se me realicen tratamientos o procedimientos que alarguen mi vida en detrimento de su calidad o viceversa.

Como todo consentimiento, la voluntad anticipada no escapa a la posibilidad de que el paciente la revoque, ya sea de forma verbal o escrita, debiendo quedar la constancia en la historia clínica. Asimismo, se define que el diagnóstico de estado terminal de una enfermedad incurable e irreversible debe ser certificado por el médico tratante y ratificado por un segundo médico en la historia clínica del paciente. 
Se prescribe que cuando una persona presente una enfermedad terminal, incurable e irreversible y no haya expresado su voluntad estando en ese momento incapacitada para expresarla, "la suspensión de los tratamientos o procedimientos será una decisión del cónyuge o concubino o, en su defecto, de los familiares en primer grado de consanguinidad ". El decreto, por otro lado, establece que será indicada técnicamente por el médico tratante y decidida por cónyuge, concubino o familiares de primer grado de consanguinidad en acuerdo con el médico. Posteriormente hace referencia a que en caso de que no haya unanimidad entre los familiares referidos, "la decisión final corresponderá al médico tratante, cuya actuación estará determinada por el estado actual del conocimiento de las ciencias médicas en relación al caso concreto y, deberá estar exenta de toda practica que conduzca a la eutanasia directa activa o a la futilidad terapéutica, vedadas al ejercicio profesional en el marco del respeto a la dignidad de la persona".

Esta ley mandata que en el caso de niños, adolescentes o personas declaradas incapaces, la suspensión de los tratamientos o procedimientos si correspondiere, será indicada técnicamente por el médico tratante conforme al estado actual del conocimiento de las ciencias médicas en relación al caso concreto y, en caso de duda razonable, decidida por sus padres en ejercicio de la patria potestad o su tutor en acuerdo con el médico tratante. Se plantea que la decisión recaerá sobre sus padres o tutores, pero luego expone el escenario en el que los niños, adolescentes o incapaces sean capaces de discernir o tener la suficiente madurez para participar en la decisión, y establece que en ese caso la decisión igualmente la tomará el representante legal pero consultando con el afectado y el médico tratante. No debemos olvidar que cuando se realiza una voluntad anticipada se está solicitando o rechazando un procedimiento o tratamiento médico; y por lo tanto, el accionar de los médicos debería ser guiado con lo que se establece en artículo 11 bis del Código de la Niñez y la Adolescencia (Ley No 17.823). Este artículo ordena que "de acuerdo a la edad del niño, niña o adolescente se propenderá a que las decisiones sobre métodos de prevención de la salud sexual u otros tratamientos médicos que pudieran corresponder, se adopten en concurrencia con sus padres u otros referentes adultos de su confianza, debiendo respetarse en todo caso la autonomía progresiva de los adolescentes. En caso de existir riesgo grave para la salud del niño, niña o adolescente y no pudiera llegarse a un acuerdo con éste o con sus padres o responsables del mismo en cuanto al tratamiento a seguir, el profesional podrá solicitar el aval del Juez competente en materia de derechos vulnerados o amenazados de ni- ños, niñas y adolescentes, quien a tales efectos deberá recabar la opinión del niño, niña o adolescente, siempre que sea posible".

Cuando se haya decidido la suspensión de un tratamiento, se deberá comunicar a la Comisión de Bioética de la institución, que debe resolver la situación en 48 horas. Si no se pronuncia en ese plazo "se considerará tácitamente aprobada la suspensión del tratamiento". Las instituciones después comunican todos los casos a la Comisión de Bioética y Calidad Integral de la Atención de la Salud del Ministerio de Salud Pública.

Otro artículo llamativo de la ley analizada es el $9^{\circ}$, que establece que el médico podría esgrimir objeción de conciencia "ante el ejercicio del derecho del paciente objeto de esta ley". El artículo 18 del decreto establece que en caso de existir objeción de conciencia por parte del médico tratante se debe derivar al paciente a otro profesional para que se garantice su adecuada atención; y luego define la objeción de conciencia como "la decisión individual de aquéllos que están involucrados en la práctica de un procedimiento de salud, de abstenerse de realizar un acto médico científico y legalmente aprobado, invocando la trasgresión que la ejecución de dicho acto implica para su conciencia, o valores filosóficos o religiosos". Si bien en muchos casos es necesaria la figura de la objeción de concien$\mathrm{cia}^{(4,5)}$, este es otro de los aspectos incomprensibles de esta ley. A la postre, luego de analizada la ley -y más precisamente analizado el $1^{\circ}$ artículo- el médico sólo podría -por no decir que debería- objetar la voluntad realizada por el paciente cuando lo que se solicite sea lo que se establece en el quinto inciso del $1^{\circ}$ artículo, es decir, cuando se soliciten tratamientos considerados fútiles; y de ninguna manera podrá objetar lo establecido en el segundo inciso de ese mismo artículo por ser considerada esa conducta lo que mandata la lex artis.

La ley además establece que son los prestadores de salud quienes deben garantizar el cumplimiento de las voluntades anticipadas; y como todo acto médico, el profesional debe dejar todo registrado en la historia clínica del paciente.

Si bien nada dispone la ley en referencia a la necesidad de "actualizar" las voluntades anticipadas realizadas, el carácter dinámico de la vida de la persona así como la posición frente a las distintas situaciones según el momento vital, haría imprescindible que se realice una renovación de las directivas con cierta perio$\operatorname{dicidad}^{(6)}$.

En definitiva: es una ley con una muy buena intención -dar un marco legal para consagrar el derecho de autonomía del paciente de manera anticipada brindando seguridad a todos los actores- ${ }^{(7)}$ pero con algunos aspectos que conspiran contra ese propósito. 


\section{Abstract}

Act 18.473 and Decree 385/013 which regulates it, were intended to provide a normative framework for individuals to state their preferences about certain medical acts when they are still capable of consenting to them, exercising their autonomy in advance, in light of the potential loss of their decision-making capacity. Therefore, the fact of performing or not a medical act, will not depend on the consent capacity of the individual at that precise moment, what differentiates it from the regular informed consent.

This article aims to analyse the possible inconsistencies between what the law intended to achieve and what is actually authorized today. Certain aspects studied could at least partially explain why this norm is still very hard to enforce even after being effective for over 12 years.

\section{Resumo}

A Lei $n^{\circ} 18.473$ e o Decreto que a regulamenta (385/013) foram concebidos com o objetivo de dar um marco normativo à possibilidade de uma pessoa estabelecer suas preferências em relação a determinados atos médicos quando ainda está em condições de consentir; exercer previamente a sua autonomia perante a eventual perda da capacidade de decisão. Portanto, a realização ou não de um procedimento médico não dependerá da capacidade da pessoa de consentir naquele momento; isso é o que o torna diferente do consentimento informado usual.
O objetivo deste artigo é analisar as possíveis discrepâncias que existem entre o que se pretendia alcançar ao criar a lei e o que realmente pode ser feito. Certos aspectos analisados poderiam explicar, pelo menos em parte, por que essa lei, que já tem mais de 12 anos de sua promulgação, continua sendo muito difícil de implementar.

\section{Bibliografía}

1. Rodríguez Almada H, Revetria Bentancor M. Consentimiento informado y voluntad anticipada. En: Rodríguez Almada H, coord. Medicina Legal: derecho médico. $2^{\mathrm{a}}$ ed. Montevideo: Oficina del Libro-FEFMUR 2020:149-60.

2. Figueroa PR. Instrumentos legales en la toma de decisiones médicas en cuadros crónicos terminales. Bioética 1998, 6(1):7-12.

3. Rodríguez Almada H. La legislación uruguaya sobre las directivas de voluntad anticipada. En: Dadalto L, coord. Bioética e diretivas antecipadas de vontade. Curitiba: Prismas, 2014:199-215.

4. Rodríguez Almada H. La objeción de conciencia en la normativa uruguaya. Arch Med Int 2013; 35(2):66-8.

5. Mautone M, Rodríguez Almada H. Objeción de conciencia en el ámbito de la salud. Rev Méd Urug 2013; 29(1):40-2.

6. Pascual E, Castelló A. Perspectiva ética, deontológica y legal de las voluntades anticipadas. Gac Int Cienc Forense $2021 ; 39: 70-9$

7. Manzini JL. Las directivas anticipadas para tratamientos médicos. Jurisprudencia Argentina 2001; IV(11):40-7.

Frances Borches Duhalde, ORCID 0000-0002-4759-3830 